\title{
Clinical and Haematobiochemical Alterations Following Administration of Tramadol as Preanaesthetic Analgesic with Xylazine and Propofol Anaesthesia in Canine Ovariohysterectomy
}

\author{
Kumari Chandrakala ${ }^{1}$, A.K. Sharma ${ }^{1}$, Laxmi Kumari ${ }^{2}$ Raju Prasad $^{3}$, \\ K.K. Singh ${ }^{4}$ and Praveen Kumar ${ }^{5}$ \\ ${ }^{1}$ Department of Surgery and Radiology, ${ }^{2}$ Touring Veterinary Officer, Animal Husbandry, \\ Jharkhand, ${ }^{3}$ Department of Veterinary Pharmacology and Toxicology, \\ ${ }^{4}$ Department of Veterinary Pathology, ${ }^{5}$ Department of Veterinary Medicine, Department of \\ Veterinary Surgery and Radiology, College of Veterinary Science and Animal Husbandry, Birsa \\ Agricultural University, Kanke, Ranchi-834006, Jharkhand, India \\ *Corresponding author
}

\section{A B S T R A C T}

A total of 5 female dogs of varying age group were admitted at Ranchi Veterinary College

Keywords in Dept. of Veterinary Surgery and Radiology for elective ovariohysterectomy. All the dogs were premedicated with Atropine sulphate, s/c @ $0.04 \mathrm{mg} / \mathrm{kg} \mathrm{b.wt.} 5 \mathrm{~min}$ prior to each treatment. Xylazine @1 mg/kg b.wt -tramadol @ $3 \mathrm{mg} / \mathrm{kg}$ b.wt IM thereafter

Bitch, canine, Clinical changes, Haemato biochemical changes, Tramadol, Propofol, ovariohysterectomy. propofol to effect" IV 15 min later and maintained by C.R.I method of propofol @0.3 $\mathrm{mg} / \mathrm{kg}$ b.wt/min. Rectal temperature and respiration rate exhibited significant alterations whereas heart rate did not show a significant variation. Haemoglobin, packed cell volume, total leucocytic counts and differential leucocytic counts except lymphocytes exhibited non- significant alterations $(\mathrm{P}>0.05)$ at different intervals. The values of lymphocytes exhibited a significant fall up to $2 \mathrm{hrs}$ of observation as compared to base line value. A variable and consistent increase $(\mathrm{P}>0.05)$ in blood urea nitrogen, creatinine, ALT, total protein could be noticed at different intervals after administration of drugs. However, these changes were non-significant ( $\mathrm{p}>0.05)$ and within normal physiological limits. Whereas, glucose and AST showed the significant elevation $(\mathrm{P}<0.05)$ at different intervals of observation. It is concluded that tramadol as preanaesthetic as analgesia in xylazine and propofol induced and CRI methods for maintenance in canine ovariohysterectomy produced little variation in physiology and haematobiochemical profiles.

\section{Introduction}

Total intravenous anaesthesia (TIVA) is a technique that allows for the continuous administration of an intravenous anaesthetic agent to maintain adequate depth of anaesthesia to allow protracted and smooth surgical interferences. It become a popular technique because of its advantages compared with inhalant techniques and the development of drugs such as propofol and short acting opioids as well as infusion systems (Cicek $e t$ al., 2005). Propofol is a non-barbiturate, phenolic intravenous injectable and GABA action enhancer anaesthetic agent. Rapid onset of action is caused by rapid uptake 
(lipophilic) into the CNS. The short action and rapid smooth emergence results from rapid redistribution from the brain to other tissues and efficient elimination from plasma by metabolism. Xylazine is the first alpha- 2 agonist to be used by veterinarians and has been found to have potent sedative effect in animals. In most species, the onset of sedation and analgesia is rapid after parentral administration of xylazine. In dogs, peak sedation and analgesia develops within 15 min and persists for 1 to $2 \mathrm{hrs}$ after administration of xylazine HCL. Tramadol is a centrally acting weak $\mu$-receptor agonist which inhibits noradrenaline re-uptake as well as promotes serotonin release, potentiates the monoaminergic system and can be used to treat moderate and severe pain (Jamuna and Nicolas, 2015. For this reason, tramadol is considered as an "atypical opioid" and is only partially inhibited by naloxone, an opioid antagonist (McMillan et al., 2008). Many published studies have described using the combination of general anesthetic drugs with opioids to promote balanced anesthesia (Coetzee et al., 1996; Shipton et al., 2003). However, the use of opioids has been reported to possess some immunosuppressive effects (Yokota et al., 2000). This paper deals the clinical and haematobiochemical changes following administration of tramadol as preanaesthetic in combination of xylazine and propofol induced along with maintenance of continuous rate infusion technique of propofol in canine ovariohysterectomy.

\section{Materials and Methods}

A total of 5 female dogs of 1- 1.5 years of were admitted at Ranchi Veterinary College in Dept. of Veterinary Surgery and Radiology for elective ovariohysterectomy. All the dogs were premedicated with Atropine sulphate, s/c @ $0.04 \mathrm{mg} / \mathrm{kg}$ b.wt. $5 \mathrm{~min}$ prior to each treatment. Xylazine @ 1 mg/kg b.wt tramadol @ 3 mg/kg b.wtIM thereafter propofol to effect" IV $15 \mathrm{~min}$ later and maintained by C.R.I method of propofol @ 0.3 $\mathrm{mg} / \mathrm{kg} \mathrm{b}$.wt/min. Owner consent for the use of the dogs and institutional ethical approval was obtained prior to inclusion of dogs in the study. Animals were admitted to the R.V.C Clinical complex in the morning of the surgery with overnight fasting and 6hrs withheld of water.

Right flank area was prepared aseptically for performing ovariohysterectomy. Area of cephalic/sephanous vein was prepared for collection of blood and infusion of drug. The animals were weighed just before the administration of atropine-sulphate. Rectal temperature, heart rate, respiration rate were recorded and blood was collected to obtain haemoglobin, packed cell volume, total leucocytic count, differential leucocytic count, serum glucose, SGPT (ALT), SGOT (AST), total serum protein, blood urea nitrogen and serum creatinine value before the operation to obtain the base value (Ohr).The cephalic/sephanous vein was catheterised using preheparinised silicon catheter to facilitate the collection of blood sample.

Following administration of anaesthetic agent as per schedule, propofol 'to effect' was injected intravenously in each animal to produce general anaesthesia till the loss of pedal reflex which served as guide for the development of surgical anaesthesia. After complete cessation of jaw muscle reflex laryngoscope was used for intubation of endotracheal tube to maintain proper ventilation of anesthetized animals. Ovariohysterectomy was performed after attainment of complete surgical anesthesia by flank method as per standard protocol.

Following administration of $\operatorname{drug}(\mathrm{s})$, different clinical, and haemato- biochemical parameters were recorded at the time interval of 0 (base line), 10, 20, 30, 45, 60, 90 and 120 minutes of drugs administration. Venous 
blood samples were collected at 0 (base line), 30, 60, 120 minutes, $4 \mathrm{hrs}$ and $24 \mathrm{hrs}$ after injection of drugs for the estimation of haematological $(\mathrm{Hb}, \mathrm{PCV}, \mathrm{TLC}$ and DLC) and biochemical parameters viz. BUN, Creatinine, Glucose, ALT, AST and total protein.

\section{Statistical Analysis}

ANOVA (Analysis of variance) and DMRT (Duncan Multiple Range Test) were used to compare the means at different intervals with base values as per the method suggested by Snedecor and Cochran (2004).

\section{Results and Discussion}

There was a non-significantly $(\mathrm{P}>0.05)$ decrease in the rectal temperature at 10, 20 and $30 \mathrm{~min}$ intervals and thereafter it decreased further and turned out to be significant $(\mathrm{P}<0.05)$ in comparison to the base line throughout the observation period (Table 1). Decrease in rectal temperature after onset of effect might be attributed to decrease in heat production due to decrease muscular activity and due to direct effect of drugs on hypothalamus (Virtanen, 1989). Activation of alpha-2 receptor by xylazine, which mediate hypothermia (Lamke, 2004) in combination with a reduced metabolic rate and muscle activity (Ponder and Clark, 1980; Virtanen, 1989) along with depression of thermoregulatory center might have caused hypothermia.

Respiration rate showed a significant $(\mathrm{P}<0.05)$ decrease at $30 \mathrm{~min}$ as compared to baseline, however, it fluctuated nonsignificantly $(\mathrm{P}>0.05)$ at all other intervals, in the study, as compared to the baseline (Table 1). Natalini et al., (2007) reported that absence of clinically significant respiratory depression is considered one of the greatest advantages of using tramadol for pain control in human in comparison with other opioides which support our findings. Anandmay et al., (2012) reported significant decrease in respiration rate after propofol and buprenorphine anaesthesia in atropinized dog.

Heart rate was increased marginally $(\mathrm{P}>0.05)$ at 10 and $20 \mathrm{~min}$ then decreased gradually, however, the values were non-significant $(\mathrm{P}>0.05)$ up to $60 \mathrm{~min}$ from the base line (Table 1). Further, the values recorded at 90 and $120 \mathrm{~min}$ of observation showed a nonsignificantly $(\mathrm{P}>0.05)$ increase and returned towards the baseline values. Initial increase in heart rate after premedication might be attributed to the effect of atropine. The increase in heart rate by atropine is due to the antagonistic activity of atropine with acetylcholine at post ganglionic effector sites (Innes and Nickerson, 1975). This is accordance with the earlier studies in which anticholinergic atropine and glycopyrrolate were found capable of reversing alpha-2agonist-induced bradycardia in dogs and caused tachycardia and hypertension (Alibhai et al., 1996).

Haemoglobin, packed cell volume, total leucocytic counts and differential leucocytic counts except lymphocytes exhibited nonsignificant fall $(\mathrm{P}>0.05)$ at different intervals (Table 2). The values of lymphocytes exhibited a significant fall up to $2 \mathrm{hrs}$ of observation as compared to base line value. Whereas, the values recorded at 4 and $24 \mathrm{hrs}$ were non-significant as compared to baseline value. The decrease in haematological parameters might be due to shifting of fluids from the extravascular compartment to the intravascular compartment in order to maintain the cardiac output in the animals (Wagner et al., 1991) or due to haemodilution in response to fluid therapy (Skarda and Muir, 1994) or due to splenic pooling of RBC. This hypothesis can be confirmed by studies in dogs which demonstrated that propofol does 
not cause measurable splenic enlargement (Wilson et al., 2004). Besides, Wilson et al., (2004) described a lack of correlation between packed cell volume and spleen size following the anesthetic protocols with propofol, suggesting sequestration of red blood cells in nonsplenic sites. The decrease in haematological parameters after epidural administration of tramadol has also been reported by various workers ( $\mathrm{Lu}$ et al., 2012; Turi et al., 2015). After recovery, the TLC value increased and returned near to baseline. This increase in TLC probably may be due to excitement, pain or apprehension at the time of recovery from anaesthesia causing the release of epinephrine resulting in the redistribution of leucocytes into the larger vessels with increased blood flow which results in a flushing effect. Gill et al., (1996) recorded a similar rise in TLC values after surgery in dogs anaesthetized with propofol. The changes in lymphocyte count in each group varied according to the neutrophil count i.e., with the rise in neutrophil count a corresponding decrease in lymphocyte counts. A decreasing trend in the eosinophils post anaesthesia could be observed in all the animals. The transient increase in monocyte at initial intervals may be attributed to steroid release provoked by stress due to anaesthesia. Such an effect has reported in dogs injected with ACTH (Schalm et al., 1975).

A variable and consistent increase $(\mathrm{P}>0.05)$ in blood urea nitrogen, creatinine, ALT and total protein could be noticed at different intervals after administration of drugs (Table 3). However, these changes were non-significant ( $>0.05$ ) and within normal physiological limits, whereas, glucose and AST showed the significant variation $(<0.05)$.

The maximum rise in glucose level could be recorded at one hour of observation. The glucose level almost returned to pre injection value by 24 hours of observation. However, no significant $(\mathrm{P}>0.05)$ difference was recorded at any interval Hyperglycemia was also recorded after administration of propofolmidazolam (Bayan et al., 2002) and propofolbuprenorphine, propofol-meperidine and propofol-pentazocine (Anandmay, 2009) in canine. Marked hyperglycemia at $1 \mathrm{hrs}$ was further supported by Kumar et al., (2010) after administration of propofol premedicated with cannabis indica (Bhang) extract in dogs.

Rise in glucose level may be due to activation of the sympathoadrenal system releasing adrenaline which in turn mobilized glycogen from liver during anaesthesia. Clarke (1968) and Allison et al., (1969) have suggested that the stress with anaesthesia and surgery lead to alteration in endocrine secretion of insulin antagonists such as growth hormone. Cortisol and catecholamine causing temporary diabetic state by gluconeogenesis and glycogenolysis as well as decrease in peripheral use of glucose (Desborough, 2000). Alpha-2 agonist have been reported to induced an increase in serum glucose by suppressing insulin release, stimulating glucagon release, or both, in $\alpha$ and $\beta$ cells of the pancreas, respectively (Brockman, 1981; Angel and Langer, 1988). In the present study the increased serum glucose level might be attributed to decreased membrane transport of glucose, decreased glucose utilization, impaired insulin activity or increased concentration of adrenocortical hormones. Bayan et al., (2002) also assigned the same reason for increased level.

AST activity is very sensitive to so many factors such as anaesthesia (Kumar and Thurman, 1978), hypoxia, stress due to anaesthesia and surgery (Davies, 1990), cardiac, skeletal and hepatic cell damage (Harper, 1971) and other other haemodynamic changes due to metabolism of anaesthesia and toxins. 
Table.1 Mean \pm S.E. value of rectal temperature $(0 F)$, respiration rate (breaths $/ \mathrm{min}$ ) and heart rate (beats/min) before and after administration of tramadol during propofol anaesthesia in canine ovariohysterectomy

\begin{tabular}{|c|c|c|c|c|c|c|c|c|}
\hline \multirow{2}{*}{ Parameters } & \multicolumn{8}{|c|}{ Period of observation (in minutes) } \\
\hline & 0 & 10 & 20 & 30 & 45 & 60 & 90 & 120 \\
\hline $\begin{array}{l}\text { Rectal } \\
\text { temperature }\end{array}$ & $\begin{array}{l}102.20 \\
\pm 0.30^{c}\end{array}$ & $\begin{array}{l}102.04 \\
\pm 0.26^{c}\end{array}$ & $\begin{array}{l}101.76 \\
\pm 0.25^{\mathrm{dc}}\end{array}$ & $\begin{array}{c}101.42 \\
\pm 0.32^{\mathrm{abc}}\end{array}$ & $\begin{array}{l}101.06 \\
\pm 0.31^{a b}\end{array}$ & $\begin{array}{l}101.00 \\
\pm 0.24^{\mathrm{ab}}\end{array}$ & $\begin{array}{l}100.84 \\
\pm 0.36^{\mathrm{a}}\end{array}$ & $\begin{array}{l}100.92 \\
\pm 0.46^{\mathrm{ab}}\end{array}$ \\
\hline $\begin{array}{l}\text { Respiration } \\
\text { rate }\end{array}$ & $\begin{array}{c}28.40 \\
\pm 2.79^{b}\end{array}$ & $\begin{array}{c}25.20 \\
\pm 2.06^{\mathrm{ab}}\end{array}$ & $\begin{array}{c}21.60 \\
\pm 4.10^{\mathrm{ab}}\end{array}$ & $\begin{array}{c}17.40 \\
\pm 3.03^{\mathrm{a}}\end{array}$ & $\begin{array}{c}22.00 \\
\pm 3.58^{\mathrm{abA}}\end{array}$ & $\begin{array}{c}25.40 \\
\pm 3.94^{\mathrm{ab}}\end{array}$ & $\begin{array}{c}31.20 \\
\pm 4.45^{b}\end{array}$ & $\begin{array}{c}28.40 \\
\pm 2.23^{b}\end{array}$ \\
\hline Heart rate & $\begin{array}{r}79.20 \\
\pm 6.74 \\
\end{array}$ & $\begin{array}{l}85.80 \\
\pm 7.94 \\
\end{array}$ & $\begin{array}{l}94.00 \\
\pm 7.64 \\
\end{array}$ & $\begin{array}{c}92.80 \\
\pm 11.71 \\
\end{array}$ & $\begin{array}{c}90.80 \\
\pm 13.53 \\
\end{array}$ & $\begin{array}{l}88.40 \\
\pm 6.31 \\
\end{array}$ & $\begin{array}{r}80.80 \\
\pm 6.41 \\
\end{array}$ & $\begin{array}{l}83.20 \\
\pm 5.75 \\
\end{array}$ \\
\hline
\end{tabular}

Value (Mean \pm S.E) bearing different superscripts in a row vary significantly $(\mathrm{P}<0.05)$.

Table. 2 Mean \pm S.E. value of haemoglobin (gm/dl), packed cell volume (PCV \%), total leucocyte count (TLC), differential leucocyte count (Neutrophils, Lymphocytes, Eosinophils, Monocytes) before and after administration of tramadol during propofol anaesthesia canine ovariohysterectomy

\begin{tabular}{|l|c|c|c|c|c|c|}
\hline \multirow{2}{*}{ Parameters } & \multicolumn{6}{|c|}{ Period of observation (in Hours) } \\
\cline { 2 - 7 } & $\mathbf{0}$ & $\mathbf{0 . 5}$ & $\mathbf{1}$ & $\mathbf{2}$ & $\mathbf{4}$ & $\mathbf{2 4}$ \\
\hline $\mathrm{Hb}(\mathrm{gm} / \mathrm{dl})$ & 15.04 & 15.16 & 15.04 & 15.12 & 15.08 & 15.04 \\
& \pm 0.76 & \pm 0.56 & \pm 0.72 & \pm 0.71 & \pm 0.73 & \pm 0.77 \\
\hline PCV (\%) & 45.12 & 45.48 & 45.12 & 45.36 & 45.24 & 45.12 \\
& \pm 2.27 & \pm 1.68 & \pm 2.17 & \pm 2.14 & \pm 2.18 & \pm 2.31 \\
\hline TLC (x10 $\left.{ }^{3}\right)$ & 7.47 & 7.30 & 7.27 & 7.37 & 7.41 & $7.50 \pm 0.57$ \\
& \pm 0.58 & \pm 0.56 & \pm 0.55 & \pm 0.58 & \pm 0.58 & 65.70 \\
\hline Neutrophils (\%) & 64.99 & 64.93 & 65.20 & 65.42 & 65.57 & \pm 1.57 \\
& \pm 1.57 & \pm 1.59 & \pm 1.59 & \pm 1.56 & \pm 1.56 & 24.57 \\
& 24.84 & 23.94 & 23.60 & 23.70 & 24.23 & $\pm 0.34^{\mathrm{ab}}$ \\
\hline Lymphocytes(\%) & $\pm 0.30^{\mathrm{b}}$ & $\pm 0.41^{\mathrm{ab}}$ & $\pm 0.39^{\mathrm{a}}$ & $\pm 0.35^{\mathrm{a}}$ & $\pm 0.29^{\mathrm{ab}}$ & 7.20 \\
& 7.24 & 7.06 & 6.83 & 6.97 & 7.13 & \pm 0.45 \\
\hline Eosinophils (\%) & \pm 0.34 & \pm 0.47 & \pm 0.40 & \pm 0.40 & \pm 0.42 & 6.11 \\
& 5.91 & 6.22 & 6.21 & 6.15 & 6.09 & \pm 0.07 \\
\hline Monocytes (\%) & \pm 0.14 & \pm 0.13 & \pm 0.13 & \pm 0.13 & \pm 0.08 & \\
& &
\end{tabular}

Value bearing different superscript in a row differed significantly $(\mathrm{P}<0.05)$ 
Table.3 Mean \pm S.E. value of blood urea nitrogen $(\mathrm{mg} / \mathrm{dl})$, creatinine, glucose, ALT, AST and total protein before and after administration of tramadol during propofol anaesthesia in canine ovariohysterectomy

\begin{tabular}{|l|c|c|c|c|c|c|}
\hline \multirow{2}{*}{ Parameters } & \multicolumn{7}{|c|}{ Period of observation (in hours) } \\
\cline { 2 - 7 } & $\mathbf{0}$ & $\mathbf{0 . 5}$ & $\mathbf{1}$ & $\mathbf{2}$ & $\mathbf{4}$ & $\mathbf{2 4}$ \\
\hline BUN (mg/dl) & 12.05 & 12.52 & 12.65 & 12.80 & 12.74 & 12.28 \\
& \pm 1.71 & \pm 1.71 & \pm 1.95 & \pm 2.08 & \pm 2.02 & \pm 1.79 \\
\hline Creatinine & 1.14 & 1.18 & 1.24 & 1.32 & 1.20 & 1.14 \\
(mg/dl) & \pm 0.08 & \pm 0.06 & \pm 0.07 & \pm 0.11 & \pm 0.07 & \pm 0.06 \\
\hline Glucose & 66.50 & 69.82 & 82.60 & 77.20 & 68.01 & 65.44 \\
(mg/dl) & $\pm 5.36^{\mathrm{a}}$ & $\pm 4.95^{\mathrm{ab}}$ & $\pm 5.08^{\mathrm{c}}$ & $\pm 4.62^{\mathrm{ab}}$ & $\pm 5.31^{\mathrm{ab}}$ & $\pm 5.39^{\mathrm{a}}$ \\
\hline ALT (IU/L) & 36.49 & 36.97 & 37.33 & 37.11 & 35.85 & 34.19 \\
& \pm 2.77 & \pm 3.57 & $\pm 3.42^{\mathrm{A}}$ & \pm 3.24 & \pm 2.67 & \pm 3.08 \\
\hline AST (IU/L) & 36.06 & 37.90 & 43.42 & 37.59 & 36.38 & 35.76 \\
& $\pm 3.36^{\mathrm{ab}}$ & $\pm 2.91^{\mathrm{ab}}$ & $\pm 4.15^{\mathrm{b}}$ & $\pm 2.83^{\mathrm{ab}}$ & $\pm 3.26^{\mathrm{ab}}$ & $\pm 3.32^{\mathrm{a}}$ \\
\hline Total protein & 6.34 & 6.34 & 6.50 & 6.25 & 6.47 & 6.29 \\
(gm/dl) & \pm 0.23 & \pm 0.27 & $\pm 0.56^{\mathrm{AB}}$ & $\pm 0.45^{\mathrm{AB}}$ & \pm 0.50 & \pm 0.44 \\
\hline
\end{tabular}

Value bearing different superscripts in small letter within groups differed significantly $(\mathrm{P}<0.05)$

Tramadol is cleared by hepatic (cytochrome $\mathrm{P}_{450}$ ) and renal metabolism (Sandhu, 2010). Propofol along with ketamine, tromadol, and butorphanol are mainly metabolized in liver. So the transient increase in AST level might be due to hepatic metabolism of these drugs which returned back to the normal physiological level indicating no undesirable effect on liver.

It is concluded that tramadol as preanaesthetic as analgesia in xylazine and propofol induced and CRI methods for maintenance in canine ovariohysterectomy produced little variation in physiology and haemato-biochemical profiles.

\section{Acknowledgement}

Authors are very thankful to Director Research, Birsa Agricultural University and Dean, Ranchi Veterinary College, BAU for providing necessary financial assistance.

Conflict of Interest: The authors do not hold any financial and personal relationships with other people or organizations that might inappropriately influence or bias this work.

\section{References}

Alibhai, H.I.K., Clarke, K.W. and Lee, Y.H. 1996. Cardiopulmonary effects of combinations of medetomidine hydrochloride and atropine sulphate in dogs. Vet Rec., 138: 11-13.

Allison, S.P., Tomlin, P.J. and Chamberlain, M. J. 1969. Some effect of anaesthesia and surgery on carbohydrate metabolism. Br. J. Anaesth., 41: 588.

Anandmay, A.K. 2009. Evaluation of propofol following premedication with buprenorphine, meperidine and pentazocine in atropinized dogs. Submitted to Birsa Agricultural University for award of MVSc degree programme.

Anandmay, A.K., Dass, L.L. and Sharma, A.K. 2012. Clinico- anaesthetic changes following administration of propofol alone and in combination of buprenorphine in dogs. Indian Vet. J., 
89(10): 77-79.

Angel, L. and Langer, S.J. 1988. Adrenergic induced hyperglycemia in anaesthetized rats: involvement of peripheral alpha ${ }_{2}$ adereno-ceptors. European J. Pharmacol., 154: 191-196.

Bayan, H., Sharma, K.K. and Lahon, D.K. 2002. Cardiopulmonary changes during propofol anaesthesia in canine. Indian Vet. J., 79(12): 24-25.

Brockman, R.P. 1981. Effect of xylazine on plasma glucose, glucagons and insulin concentration in sheep. Res. Vet. Sci., 30: 383-384.

Cicek, M., Koroglu, A., Demirbilek, S., Teksan, H. and Ersoy, M.O. 2005 Comparison of propofol-alfentanil and propofolremifentanil anaesthesia in percutaneous nephrolithotripsy. European J. Anaesthesiol., 22: 683688.

Clarke, R.S.J. 1968. The influence of anaesthesia with thiopentone and propandid on the blood sugar level. $B r$. J. Anaesth., 7(4): 40-46.

Coetzee, J.F., Maritz, J.S. and Du Toit, J.C. 1996. Effect of tramadol on depth of anaesthesia. Br. J. Anaesth., v. 76, p.415-418.

Davies, C. 1991. Excitatory phenomena following the use of propofol in dogs. $J$. Vet. Anaesth., 18: 48-51.

Desborough, J.P. 2000. The stress response to trauma and surgery. Br. J. Anaesth., 85(1): 109-117.

Gill, J.R., Rodrriguez, J.F., Ezquerre, L.J., Vives, M.A., Jimenez, J. and Uson, J.M. 1996. Development of anaesthesia and changes in the blood parameters in dogs medicated with propofol. Medicina-Veterinaria, 13(4): 242-246.

Harper, H.A. 1971. Review of physiol. Chem., Lange medical Publication, Loss, C.A.

Innes, I.R. and Nickerson, M. 1975. Atropine, scopolamine and related antimuscarinic drugs:In Goodman, L.S., Gilman, A.
Pharmacological basis of therapeutics, $5^{\text {th }}$ ed. New York, Macmillan Publishing Co.Inc, pp.514-532.

Jamuna, T. and Nicolas Israel, Y. 2015. Prospective and comparative study of the analgesic effect of intravenous $2 \%$ xylocard versus intravenous tramadol in ameliorating propofol injection pain. $J$. Evid. Based Med. Health., 2: 3529-39.

Kumar, A. and Thurmon, J.C. 1978. Physiolologic, haemocytologic and biochemical effects of acetylpromazine with and without premedication in goats. Indian Vet. J., 55: 199- 201.

Kumar, S.S.H., Dass, L.L. and Sharma, A.K. 2010. Cannabis indica as a preanesthetic to propofol anaesthesia in dogs. J. Appl. Animal Res., 37: 125-127.

Lemke, K.A. 2004. Understanding the physiology of perioperative pain. Can. Vet. J., 45: 405 - 413.

Lu, D.Z., Fan, H.G., Jiang, S., Zhang, L.S., Ma, K., Yu, S.M., Tan, L.J. and Wang H.B. 2012. Cardiopulmonary, biochemical and haematological effect of the Teletamine/ ZolazepamXylazine-Tramadol combination to provide anaesthesia in miniature pigs. $J$. Integrative Agri., 11(8): 1340-1346.

McMillan, C. J., Livingston, A. and Clark, C. R. 2008. Pharmacokinetics of interavenous tramadol in dogs. Canadian J. Vet. Res., 72(4): 325-331.

Natalini, C.C., Polydoro, A.S. and Crosignani, N. 2007. Effect of morphine or tramadol on thiopental anaesthetic induction dosage and physiological variables in halothane anaesthetized dogs. Acta Scientiae Veterinariae., 35: 161-166.

Ponder, S.W. and Clarke, W.G. 1980. Pharmacokinetics of subcutaneous and intramuscular butorphanol in dog. $J$. Pharm. Sci., 69: 801-803.

Sandhu, H.S. 2010. Essential of veterinary pharmacology. $\quad 2^{\text {nd }} \quad$ ed.Kalyani publication, New Delhi, India. 
Schalm, O.W., Jain, N.C. and Carrol, E.J. 1975. Veterinary Haematology. $3^{\text {rd }}$ Edn. Lea and Febiger Philadelphia, PP 1-778.

Shipton, E.A., Roelofse, J.A. and Blignaut, R.J. 2003. An evaluation of analgesic efficacy and clinical acceptability of intravenous tramadol as an adjunct to propofol sedation for third molar. Surgery Anesth. Prog., 50: 121128.

Skarda, R.T. and Muir, W.W.1994. Caudal analgesia induced by epidural or subarachnoid administration of detomidine hydrochloride solution in mares. American Journal of Veterinary Research, $55: 670-680$.

Snedecor, G.W. and Cochran, W.G. 2004. Statical methods 4 th Edn. Lowa State University press, Ames, lowa.

Turi, D., Sharma, A.K., Dass, L.L. and Mehta, S. 2015. Haemato-biochemical changes after epidural administration of tramadol in combination of lignocaine in goats. Indian J. Small Ruminants, 21(1): 71-75.

Virtanen, R.1989. Pharmacological profiles of medetomidine and its antagonist, antipamizole. Acta Vet. Scand., 85: 2937.

Wagner, A.E., Muir, W.W. and Hinchcliff, K.W. 1991. Cardiovascular effects of xylazine and detomidine in horses. Am. J. Vet. Res., 52: 651-657.

Wilson, D.V., Evans, A.T. and Carpenter, R.E. 2004. The effect of four anesthetic protocols on splenic size in dogs. Vet. Anaesth. Analg., 31: 102-108.

Yokota, T., Uehara, K. and Nomoto, Y. 2000. Intrathecal morphine suppresses NK cell activity following abdominal surgery. Can. J. Anaesth., 47: 303-308.

\section{How to cite this article:}

Kumari Chandrakala, A.K. Sharma, Laxmi Kumari, Raju Prasad, K.K. Singh and Praveen Kumar. 2017. Clinical and Haematobiochemical Alterations Following Administration of Tramadol as Preanaesthetic Analgesic with Xylazine and Propofol Anaesthesia in Canine Ovariohysterectomy. Int.J.Curr.Microbiol.App.Sci. 6(4): 1736-1743. doi: https://doi.org/10.20546/ijcmas.2017.604.208 